\section{Um olhar histórico e profundo sobre a construção da identidade profissional e formação acadêmica do jornalista no país}

Cristiane GERK ${ }^{1}$

LOPES, Fernanda Lima. Ser jornalista no Brasil: identidade e formação acadêmica. São Paulo: Paulus, 2013.

Ler o livro Ser jornalista no Brasil. Identidade profissional e formação acadêmica é, sem dúvida, muito estimulante para quem estuda o jornalismo no país. A busca da autora por respostas sobre esse grupo de agentes sociais com lugar privilegiado no ambiente midiático é a de muitos estudantes e pesquisadores da área. A investigação foi desenvolvida ao longo de seis anos, na Escola de Comunicação da Universidade Federal do Rio de Janeiro, e a publicação abarca parte dos resultados encontrados. Fernanda Lopes tem se dedicado ao eixo do ensino em suas pesquisas empíricas e faz teoria e prática dialogarem em vários tópicos essenciais para responder a essa pergunta tão pouco esclarecida: "Afinal, quem é o jornalista brasileiro?".

Para justificar sua pesquisa, Lopes lembra que as prerrogativas profissionais do bacharel em jornalismo estão sempre sob tensão e problematizadas. Sua intenção é, entre outras questões, investigar por que a formação acadêmica do jornalista é tão questionada. No caminho para essas respostas, muitos atores sociais dessa polêmica são colocados em diálogo pela autora, como os membros da academia, de entidades de classe, do mercado de trabalho, empresários, enfim, todos esses que ajudam a construir a identidade profissional do jornalista. Segundo a autora, nos momentos em que os sentidos que permeiam a identidade desse profissional, sobretudo devido

1 Aluna do mestrado em Mídias e Mediações, da Escola de Comunicação da Universidade Federal do Rio de Janeiro. a tensões entre esses atores, ficam mais evidentes, os valores que ajudam na investigação também sobressaem.

A obra se divide em três partes. A primeira desenvolve os conceitos de jornalismo e identidade. A segunda faz um relato cronológico de processos envolvendo o ensino de jornalismo e a profissionalização da atividade no país. Já a última aborda a formação do jornalista na primeira década do século XXI, com enfoque na polêmica sobre a obrigatoriedade do diploma.

No início da primeira parte de seu livro, Lopes faz um apontamento muito relevante para quem pretende estudar a identidade de qualquer profissional: a noção de que a identidade não pode ser tomada como fixa, imutável. Ela vai sendo construída em relações contextuais e de acordo com a realidade social do momento. Nesse sentido, são citadas as contribuições de teóricos como Zygmund Bauman e Stuart Hall. Também por essa pontuação, a autora demarca que o atual contexto de transformações sociais promovidas pela digitalização da sociedade não abarcariam uma crise do jornalismo ou do jornalista. A concepção de identidade apenas se reconfiguraria mediante a globalização, a emergência de novas tecnologias de comunicações, a aceleração das trocas materiais e simbólicas e outras características clássicas da chamada pós-modernidade.

Lopes apontou vários fatores que reforçam que a identidade é fruto de uma construção, como a inserção do homem na sociedade, a história, a psicanálise, a interação com outros, os valores, crenças, mitos, relações de poder, a memória e o savoir-faire, ou seja, as atividades às quais cada um se dedica. Tudo isso influencia na construção de uma identidade em mutação ao longo do tempo.

Depois de trabalhar com conceitos importantes para a noção de identidade, a autora passa a discutir conceitos de jornalismo. Como importante ponto de partida, ela cita as contribuições de Eduardo Meditsch, segundo quem, o jornalismo é uma forma de reprodução de conhecimento de outras esferas da vida social. A dimensão gnoseológica do jornalismo se ligaria ao fato de que ele sempre se reporta ao mundo real, e não ficcional, mesmo que a realidade se enquadre a um mundo virtualizado. Aí se fundariam, segundo a autora, as crenças sobre a verdade jornalística e o papel de mediação. O segundo âmbito do jornalismo seria o político-discursivo, um discurso autorizado e desejado entre público e fatos. A retórica jornalística, de acordo com Lopes, explora verossimilhança ao mesmo tempo em que busca um estatuto de verdade, através da norma da objetividade, ou seja, na reunião de elementos que esfumaçam o esforço retórico e revertem o discurso de aparência inquestionável, evidente, lógica. 
A terceira dimensão do jornalismo tem a ver com seu caráter atual e periódico, mesmo quando se dá em veículos da internet.

A segunda parte do livro, que traça uma cronologia sobre o ensino e a profissão, começa com os primórdios da atividade e seu estudo, nos séculos XIX e XX. O jornalismo era revestido de um caráter político e literário. Em meio a discussões sobre a valorização desse profissional, surgiram a Associação Brasileira de Imprensa e o I Congresso Brasileiro de Jornalistas, no início do século $\mathrm{XX}$, quando se pensou pela primeira vez em constituir uma escola de jornalismo no país, segundo a autora. Lopes passa seu relato por momentos importantes, como o surgimento de um campo jornalístico e do seu reconhecimento como profissão, a partir do complemento dos fazeres com saberes, valores e organização. Em 1938, um decreto instituiu o curso de jornalismo e, em 1947, nascia o primeiro curso superior, já rodeado de tensões entre a formação mais teórica ou prática, segundo a autora.

Logo a seguir, Lopes comenta sobre o momento de profissionalização do jornalismo, entre 1947 e 1962, quando transformações institucionais teriam reforçado a noção de notícia como mercadoria. O modelo americano, marcado mais pela objetividade, substituiria o francês, mais literário, e a ênfase na publicidade, nas lógicas empresariais e comerciais tomava o lugar de destaque. O "furo" passaria a ser sinônimo de altas vendas. No capítulo seguinte, a autora destrincha a criação do Decreto-Lei que estabeleceu a obrigatoriedade do diploma de jornalista no país, em 1969, e as primeiras experiências governamentais na elaboração de currículos mínimos para o curso. Esse movimento todo ocorre no período da ditadura militar.

De acordo com a autora, havia um apelo por parte dos sindicatos por uma legislação específica para a categoria jornalística, logo a regulamentação foi entendida pela maioria como uma conquista de classe. Entretanto, Lopes lembra que a implementação da medida gerou incômodo e tensão para os que já exerciam a profissão sem o diploma e para os empresários, que se preocupavam se teriam que pagar salários maiores (o que não aconteceu). Porém, tanto nos discursos de quem condenava quanto no de quem defendia o diploma, transparecia a imagem de uma profissão intelectualmente exigente.

Lopes ressalta que, na época da ditadura, ficaram reforçados os papeis de jornalistas como promotores dos valores democráticos e defensores de garantias individuais e coletivas, porta-vozes desinteressados do bem comum. A busca pela "revelação da verdade" também trouxe à tona a categoria de jornalismo investigati- vo, que marcou o jornalista como um "vigia" da sociedade, mediador entre poder público e fatos. Todos esses fatores, segundo a autora, reforçaram um papel social do jornalismo.

No último capítulo da segunda parte do livro, Lopes estuda a transição do século XX para o XXI, começando pela expansão do número de cursos de jornalismo, sobretudo particulares, que geraram inclusive desconfianças em relação à qualidade do ensino pelo meio acadêmico e organizações sindicais. Também se temia um excesso de mão de obra. A autora depois aborda o movimento crescente que demandava o reconhecimento do jornalismo como um campo específico de conhecimento, e as críticas e elogios feitos à essa intenção. Algumas iniciativas nesse sentido são esmiuçadas, como a criação da Associação Brasileira de Pesquisadores em Jornalismo (SBPJor), do Fórum Nacional de Professores de Jornalismo (FNPJ), e do primeiro mestrado em jornalismo na UFSC.

Sobre o mercado de trabalho, Lopes ressalta que a maior parte dos que concluem a faculdade não se encaminha para o exercício formalizado da profissão, mas alguns campos como os do freelancers, funcionários de canais a cabo e concursados de empresas públicas, por exemplo, cresceram. Sobre a chamada crise que se diz passar o jornalismo, a autora recorre a Michael Pollak para explicar que o sentimento de pertencimento é um dos pilares da construção identitária de um grupo, logo o jornalismo não está imune às pressões exercidas por esse contingente confuso de sujeitos no espaço digital que se dizem jornalistas. Porém, a identidade também é composta pela continuidade do grupo no tempo e pela sensação de unidade grupal, aspectos ainda fortes na dimensão profissional do jornalista.

$\mathrm{Na}$ última parte do livro, Lopes fala sobre a ação judicial que culminou, em 2009, no fim da obrigatoriedade do diploma e na implementação de propostas de diretrizes curriculares específicas para o jornalismo, separado da comunicação social. Mais uma vez, Lopes mapeia as intenções do mercado de trabalho, da academia e das associações de classe nesses temas. Aplicando um estudo sobre retórica, ela traça um perfil das intenções e ferramentas usadas pelos agentes sociais desse momento, em seus discursos em defesa ou contra as medidas, na tentativa de convencer e mobilizar afetos e lógica. Os embates sobre a exigência do diploma foram alavancados pela disputa jurídica ocorrida entre 2001 e 2009, mas a autora lembra que eles se ancoram em um cenário polarizado que remonta aos anos 1980, quando já empresários de comunicação eram contra a obrigatoriedade e entidades 
sindicais, a favor. Velhos argumentos, como os de defesa da liberdade de expressão ou da qualidade técnica e ética (em vez de apadrinhamentos), apenas teriam sido reconfigurados no novo cenário de comunicação em rede e convergência. Porém, Lopes ressalta que havia divisões até mesmo dentro dos grupos, e entre os estudantes, que acabavam, em sua maioria, defendendo o diploma obrigatório, por seguirem a lógica de que grandes empresas jornalísticas, seu foco de interesse, o exigiriam de qualquer maneira.

A autora mostra que a elaboração de diretrizes curriculares para o jornalismo deve ser contata paralelamente à do diploma, porque elas estão politicamente conectadas. As primeiras estariam ligadas ao atendimento de pressões feitas por atores sociais na ocasião da Campanha Nacional em Defesa do Diploma, encabeçada pela Fenaj. Alguns temas bem atuais estiveram presentes na discussão, como a diferenciação entre blogueiros e jornalistas profissionais, cercados dos valores éticos da classe. As diferentes falas de atores importantes desse período são descritas e analisadas pela autora.

Em suas considerações finais, Fernanda Lopes pondera que há indícios de que a imagem profissional do jornalista na atualidade já não tem a mesma força do que a alcançada no auge da modernidade. As mudanças em curso teriam contribuído para colocar em xeque crenças consagradas na identidade jornalística. Porém, o valor da liberdade, segundo ela, não sofreu tantos abalos, e se manteve junto com a defesa de valores democráticos, como um dos parâmetros mais fortes para sustentar a credibilidade e o poder dos jornalistas. Mesmo assim, é inegável que internet e as novas tecnologias tensionaram as fronteiras da identidade que se calcou nas imagens de instituições profissionais, segundo Lopes.

A contribuição de Fernanda Lopes para o meio acadêmico a partir deste livro é ampla: ela traça um mapa histórico do ensino e da prática da profissão no país, e como as diferentes etapas marcaram a formação da identidade jornalística. A partir de conceitos, como o da retórica, do que é jornalismo e identidade, ela estuda e analisa os momentos históricos à luz de conhecimentos e reflexões teóricas profundas. Deixa em aberto para serem futuramente abordadas algumas fases que passaram mais rapidamente dentre o panorama e estimula quem pretende se aprofundar em uma ou algumas das nuances e questões levantadas. É um guia e um estímulo para quem estuda o jornalismo no Brasil, sobretudo para quem quer, à luz da história, compreender o que se passa na contemporaneidade. 